\title{
A survey of robust statistics
}

\section{Stephan Morgenthaler}

\section{Erratum to: Stat. Meth. \& Appl. (2007) 15:271-293} DOI 10.1007/s10260-006-0034-4

Unfortunately, through a typesetting error, the reference list referring to the article's first part was missing. It should have been printed before the discussion on page 278:

\section{References}

1. Atkinson AC, Riani M (2000) Robust diagnostic regression analysis. Springer, Heidelberg

2. Atkinson AC, Riani M, Cerioli A (2004) Exploring multivariate data with the forward search. Springer, Heidelberg

3. Box GEP (1953) Non-normality and tests on variances. Biometrika 40:318-335

4. Davies L (1990) The asymptotics of S-estimators in the linear regression model. Ann Stat 18:1651-1675

5. Davies PL (1993) Aspects of robust linear regression. Ann Stat 21:1843-1899

6. Davies PL (1995) Data features. Stat Neerl 49:185-245

7. Donoho DL, Liu RC (1988) The "automatic" robustness of minimum distance functionals. Ann Stat 16:552-586

8. Genton MG (2001) The change-of-variance function: a tool to explore the effects of dependencies in spatial statistics. J Stat Plann Inference 98(1-2):191-209

The online version of the original article can be found under doi:10.1007/s10260-006-0034-4.

S. Morgenthaler $(\varangle)$

Institute of Mathematics, Ecole Polytechnique fédérale de Lausanne,

Lausanne, Switzerland

e-mail: stephan.morgenthaler@epfl.ch

S. Morgenthaler

EPFL FSB IMA, Station 8, 1015 Lausanne, Switzerland 
9. Hampel F, Ronchetti EM, Rousseeuw PJ, Stahel WA (1986) Robust statistics: the approach based on influence functions. Wiley, New York

10. Hampel FR (1974) The influence curve and its role in robust estimation. J Am Stat Assoc 69:383-393

11. Hodges JLJ (1967) Efficiency in normal samples and tolerance of extreme values for some estimates of location. In: Proceedings of the fifth Berkeley symposium on mathematical statistics and probability, vol 5. University of California Press, pp $163-186$

12. Huber PJ (1981) Robust Statistics. Wiley, New York

13. Kent JT, Tyler DE (1991) Redescending M-estimates of multivariate location and scatter. Ann Stat 19:2102-2119

14. Kleiner B, Martin RD, Thomson DJ (1979) Robust estimation of power spectra. J R Stat Soc Ser B 41:313-338

15. Lange KL, Little RJA, Taylor JMG (1989) Robust statistical modelling using the t-distribution. J Am Stat Assoc 84:881-896

16. Maronna RA (1976) Robust M-estimators of multivariate location and scatter. Ann Stat 4:51-67

17. Maronna RA, Stahel WA, Yohai VJ (1992) Bias-robust estimators of multivariate scatter based on projections. J Multivariate Anal 42:141-161

18. Martin RD, Yohai VJ, Zamar RH (1989) Min-max bias robust regression. Ann Stat 17:1608-1630

19. Morgenthaler S, Tukey JW (1991) Configural polysampling: a route to practical robustness. Wiley, New York

20. Pearson ES (1931) The analysis of variance in cases of non-normal variation. Biometrika 23:114

21. Rousseeuw PJ (1984) Least median of squares regression. J Am Stat Assoc 79:871-880

22. Rousseeuw PJ, Croux C (1993) Alternatives to the median absolute deviation. J Am Stat Assoc 88:1273-1283

23. Rousseeuw PJ, Leroy AM (1987) Robust regression and outlier detection. Wiley, New York

24. Stahel WA (1981) Robust estimation: infinitesimal optimality and covariance matrix estimators. Ph.D. thesis, ETH Zürich

25. Tukey JW (1960) A survey of sampling from contaminated distributions. In: Olkin I et al (eds) Contributions to probability and statistics: essays in honor of Harald Hotelling. Stanford University Press, pp 448-485

26. Tyler DE (1987) A distribution-free M-estimator of multivariate scatter. Ann Stat 15:234-251

27. Van Aelst S, Rousseeuw PJ (2000) Robustness of deepest regression. J Multivariate Anal 73(1):82-106

Furthermore, the reference list printed on page 293 refers to the section before, and should have been printed on page 292 before the rejoinder.

We apologize very much for these errors. 